\title{
Geopolymer Development by Powders of Metakaolin and Wastes in Thailand
}

\author{
Chayanee Tippayasam ${ }^{1, a}$, Sansanee Boonsalee ${ }^{3, b}$, Suvimol Sajjavanich ${ }^{2, a}$, \\ Chiara Ponzoni ${ }^{4, \mathrm{c}}$, Elie Kamse ${ }^{4, \mathrm{~d}}$ and Duangrudee Chaysuwan ${ }^{1, \mathrm{a}}$ \\ ${ }^{1}$ Department of Materials Engineering, Faculty of Engineering, Kasetsart University, Bangkok, \\ Thailand \\ 2Department of Civil Engineering, Faculty of Engineering, Kasetsart University, Bangkok, Thailand \\ ${ }^{3}$ Department of Science Service, Ministry of Science and Technology, Bangkok, Thailand \\ ${ }^{4}$ Department of Materials and Environmental Engineering, University of Modena and Reggio \\ Emilia, Italy \\ fengddc@ku.ac.tha ${ }^{\mathrm{a}}$, ssansanee@dss.go.th ${ }^{\mathrm{b}}$, chiara.ponzoni@gmail.comc and kamseuelie2001@yahoo.fr ${ }^{\mathrm{d}}$
}

Keywords: Geopolymer; Fly ash; Bagasse ash; Rice husk ash; Metakaolin

\begin{abstract}
Geopolymer has been developed as an alternative material to Portland cement. Geopolymer is based on the polymerization of alkaline activation and oxide of silicon and aluminium. These oxides can be found in many pozzolanic materials such as metakaolin and the wastes from industries and agricultures in Thailand, e.g., fly ash, bagasse ash and rice husk ash.

Pozzolanic materials were selected as source materials for making geopolymers into 4 different types. Sodium hydroxide concentration of $10 \mathrm{Molar}(10 \mathrm{MNaOH})$ and sodium silicate $\left(\mathrm{Na}_{2} \mathrm{SiO}_{3}\right)$ solutions were used as alkaline activators by the mass ratio of $\mathrm{Na}_{2} \mathrm{SiO}_{3} / \mathrm{NaOH}$ at 1.5 . The mixtures were cast in $25 \times 25 \times 25 \mathrm{~mm}$. cubes. After casting, the geopolymers were cured at $80^{\circ} \mathrm{C}$ for $24 \mathrm{hrs}$. in an oven and then at room temperature for 7 days. The pozzolanic materials effects, the $\mathrm{Si} / \mathrm{Al}$ molar ratio and the $\mathrm{Na} / \mathrm{Al}$ molar ratio were studied and characterized.

An X-ray fluorescence (XRF) was chosen to determine the percentages of silica and alumina in order to verify the proper ratio of the fly ash, Rice husk ash, Bagasse ash and Metakaolin.The study also included the impact on mechanical and physical properties such as compressive strength, water absorption, density and porosity.
\end{abstract}

\section{Introduction}

Geopolmer was first originated by Davidovits (1979) to designate a new class of three dimensional silico-aluminate materials[1]. The geopolymer is produced by totally replacing the ordinary Portland cement. Hence, the use of geopolymer concrete to replace the cement is to reduce the $\mathrm{CO}_{2}$ emissions by the cement industries [2]. Geopolymerization can be applied to utilize solid wastes and by-products containing silica and alumina which are called 'Pozzolans'. A geopolymer is environmentally friendly [3] which is attractive to increase attention in various research fields as a construction material[4]. Pozzolans from industrial and agricultural by-products such as fly ash, bagasse ash and rice husk ash were used to produce geopolymers in this research.

An industrial by-product, from power plants, which is now being used quite extensively as a pozzolan for replacing cement is fly ash. Bagasse ash is a by-product from sugar refinery whereas rice husk is a by-product from rice mill. When they are burnt both bagasse ash and rice husk ash contain around $80 \%$ of silica, silica in amorphous form suitable for use as a pozzolan[5].

Furthermore, the geopolymerization can be reacted with metakaolin, obtained by burning kaolin from Ranong province in Thailand, normally, at temperature higher than $600^{\circ} \mathrm{C}[6]$.

The main alkali solutions activated with pozzolans were sodium silicate and sodium hydroxide. In this research, the fly ash, bagasse ash, rice husk ash and metakaolin were used as the starting materials. They were studied the effects of pozzolanic materials, the $\mathrm{Si} / \mathrm{Al}$ molar ratio, the $\mathrm{Na} / \mathrm{Al}$ molar ratio and $\mathrm{Na} / \mathrm{Si}$ molar ratio for mechanical and physical properties such as compressive strength, water absorption, density and porosity. 


\section{Experimental}

\subsection{Characterization of initial materials}

Fly ash (FA) was lignite fly ash from Mae Moh power plant in the northern part of Thailand. Rice husk ash (RHA) was obtained from rice mill in the central part of Thailand. Bagasse ash (BA) was a by-product from sugar refinery at Kaset Thai Co., Ltd., in Nakhon Sawan province. Washed kaolin was obtained from Mineral Resources Development Co., Ltd., Ranong province in southern part of Thailand. FA, RHA and BA were ground by a ball mill until the mass of the fine particles retained on sieve size No.325 (aperture of $45 \mu \mathrm{m}$ ) was 1-3\%. Metakaolin (MK) was subsequently produced by burning kaolin clay at $1000^{\circ} \mathrm{C}$, for $6 \mathrm{hr}$. Table. 1 shows the chemical compositions of FA, RHA, BA and MK as determined by X-ray fluorescence (XRF) analysis. X-ray diffraction (XRD) pattern of MK, in Fig.1, present mainly MK composed of $\alpha$-quartz, metakaolinite and silicon oxide.

Tables 1 Chemical compositions of FA, RHA, BA and MK as determined by XRF (mass\%)

\begin{tabular}{|c|c|c|c|c|c|c|c|c|}
\hline $\begin{array}{c}\text { Chemical } \\
\text { composition (\%) }\end{array}$ & $\mathrm{SiO}_{2}$ & $\mathrm{Al}_{2} \mathrm{O}_{3}$ & $\mathrm{Fe}_{2} \mathrm{O}_{3}$ & $\mathrm{CaO}$ & $\mathrm{MgO}$ & $\mathrm{Na}_{2} \mathrm{O}$ & $\mathrm{K}_{2} \mathrm{O}$ & $\mathrm{SO}_{3}$ \\
\hline FA & 39.88 & 22.36 & 13.22 & 12.85 & 2.56 & 1.72 & 3.09 & 2.97 \\
\hline RHA & 94.25 & 0.52 & 0.22 & 0.70 & 0.40 & 0.05 & 2.26 & 0.82 \\
\hline BA & 75.39 & 5.44 & 3.42 & 7.89 & 1.50 & 0.30 & 3.32 & 0.39 \\
\hline MK & 53.48 & 44.08 & 0.63 & & & & 1.65 & \\
\hline
\end{tabular}

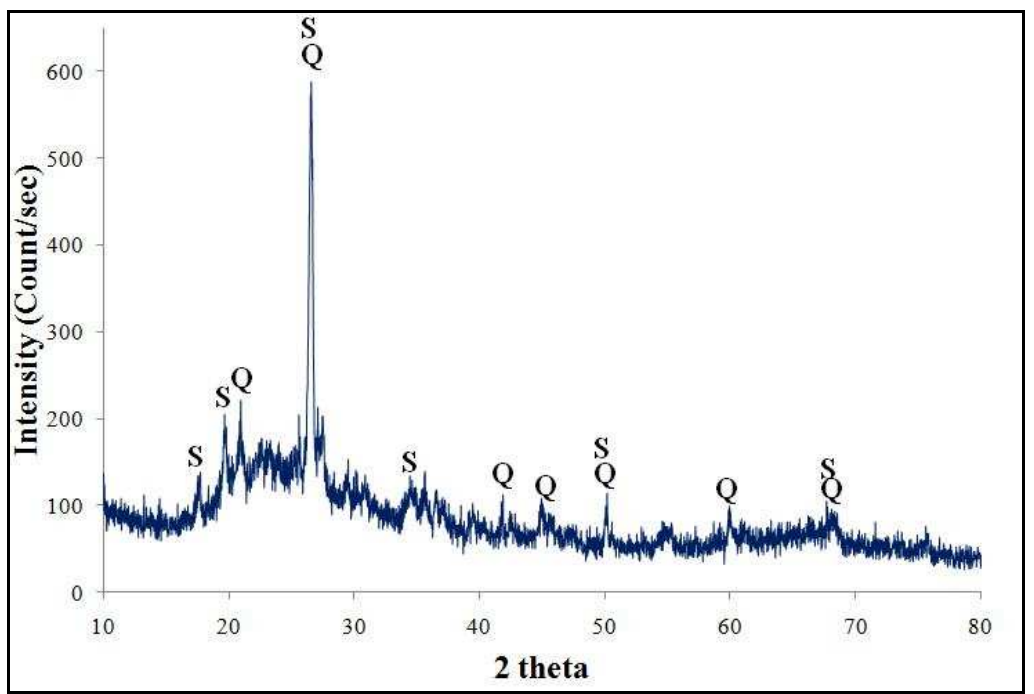

Fig. 1 XRD pattern of Metakaolin. $\mathrm{Q}=$ Quartz and $\mathrm{S}=$ Silicon oxide.

\subsection{Alkali activators}

Sodium silicate solutions $\left(\mathrm{Na}_{2} \mathrm{SiO}_{3}\right)\left(13.8 \% \mathrm{Na}_{2} \mathrm{O}, 32.2 \% \mathrm{SiO}_{2}\right.$ and $\left.54.0 \% \mathrm{H}_{2} \mathrm{O}\right)$ and $10 \mathrm{M} \mathrm{NaOH}$ solutions (commercial grade) were used as the alkali activators.

\subsection{Methodology}

\subsubsection{Mixed proportions of geopolymer paste}

FA, RHA, BA and MK were individually pre-mixed in a beaker. The mixed proportions of FA to RHA, FA to BA and FA to MK were prepared by variation to five ratios as; $0: 100,20: 80,50: 50,80: 20$ and 100:0 by weight. The ratios of solid to liquid $\left(\mathrm{Na}_{2} \mathrm{SiO}_{3}\right.$ and $10 \mathrm{MNaOH}$ ) were $80: 20,70: 30,60: 40$ and 50:50 by weight as geopolymer pastes. These proportions have difference of the $\mathrm{Si} / \mathrm{Al}$ and $\mathrm{Na} / \mathrm{Al}$ as shown in Table 2 and Fig.3 


\subsubsection{Mixing of geopolymer paste}

The solution of $\mathrm{Na}_{2} \mathrm{SiO}_{3}$ and $10 \mathrm{M} \mathrm{NaOH}$ were prepared at least 1 day prior to its use. The solution was poured into a beaker and mixed with solid homogeneously. Consequently, the pastes were poured into $25 \times 25 \times 25 \mathrm{~mm}^{3}$ acrylic moulds. The specimens were wrapped with plastic film and then cured at room temperature for $24 \mathrm{hrs}$, further removing the mold and, finally, the specimens were cured at room temperature for 7 days.

\subsection{Test of specimens}

\subsubsection{Compressive strength}

The test was done in according to the ASTM C 618. The reported results are the average of four samples at 8 days age.

\subsubsection{Water absorption, Density and Porosity}

In order to determine the water absorption, density and porosity of mortar specimens, 7 days age of four cubes from each series were oven dried at a temperature of $85^{\circ} \mathrm{C}$ for $24 \mathrm{hrs}$ and their weight were determined as the initial weight $\left(\mathrm{W}_{\mathrm{d}}\right)$. A sample was then immersed in water for $24 \mathrm{hrs}$ and weighed the sample in water as $\mathrm{W}_{\mathrm{w}}$. Finally, the saturated weight was weighed in air as $\mathrm{W}_{\mathrm{a}}$.

The water absorption was calculated using Eq.1

$$
\% \text { Water absorption }=\left(\mathrm{W}_{\mathrm{a}}-\mathrm{W}_{\mathrm{d}}\right) /\left(\mathrm{W}_{\mathrm{a}}\right) \times 100
$$

The density was calculated using Eq.2

$$
\text { Density }=\left(\mathrm{W}_{\mathrm{d}}\right) /\left(\mathrm{W}_{\mathrm{a}}-\mathrm{W}_{\mathrm{w}}\right) \times 100
$$

And the porosity was calculated using Eq.3

$$
\rho=\left(\mathrm{W}_{\mathrm{a}}-\mathrm{W}_{\mathrm{d}}\right) /\left(\mathrm{W}_{\mathrm{a}}-\mathrm{W}_{\mathrm{w}}\right) \times 100
$$

where

$\rho$ is vacuum saturated porosity $(\%)$,

$\mathrm{W}_{\mathrm{a}}$ is weight in air of saturated sample $(\mathrm{g})$,

$\mathrm{W}_{\mathrm{d}}$ is dry weight after $24 \mathrm{hrs}$ in oven at $85 \pm 5{ }^{\circ} \mathrm{C}(\mathrm{g})$ and

$\mathrm{W}_{\mathrm{w}}$ is weight in water of saturated sample $(\mathrm{g})$

The reported results are the average of four samples.

\section{Results and Discussion}

3.1. Effect of quantity of alkali liquid on compressive strength

The compressive strength of geopolymer specimens curing at room temperature and 8 days age were shown in Fig.2. 


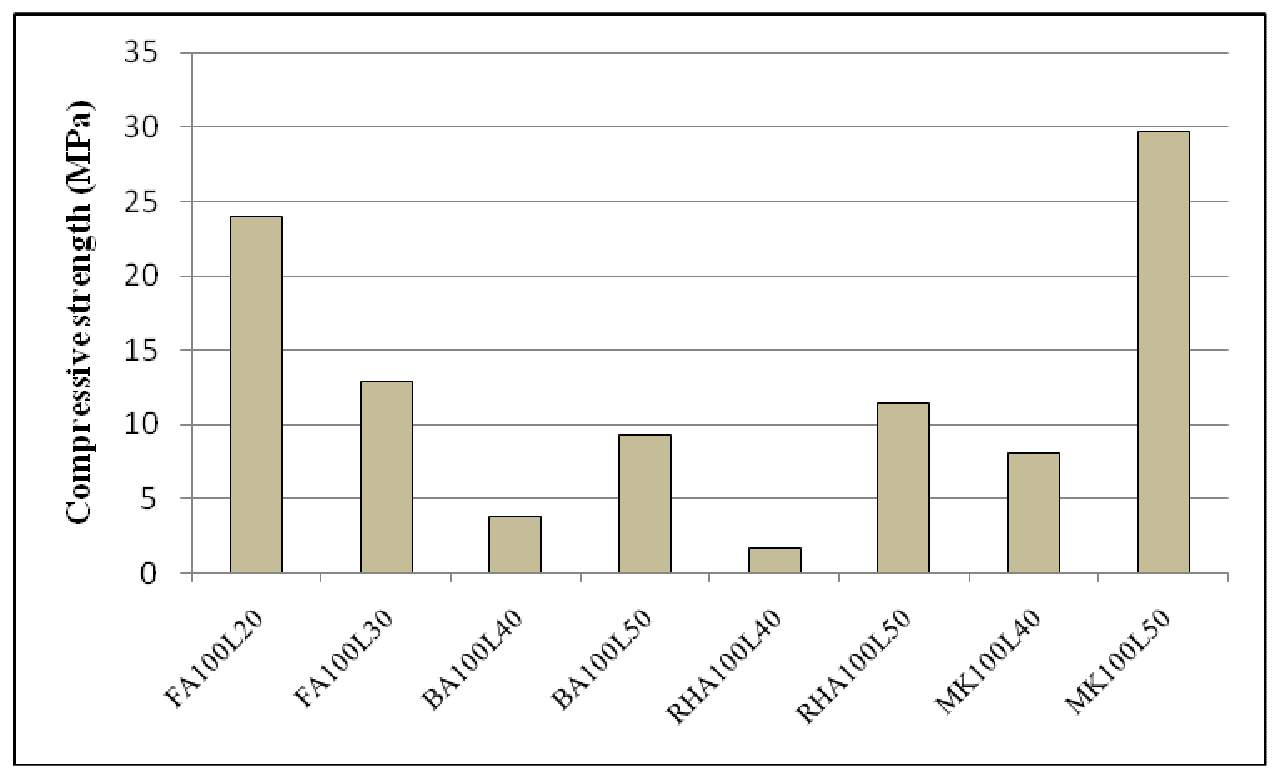

Fig. 2 Compressive strength vs. quantity of liquid alkali

From Fig. 2, the maximum compressive strength (31.57 MPa) was obtained from the specimens of MK100L50 (100\% metakaolin and 50\% liquid alkali) while the minimum strength (1.66 MPa) was from RHA100L40 (100\% rice husk ash and 40\% liquid alkali), therefore, the metakaolin would be focused in its activity. In additional, it was found that the compressive strength of geopolymer with FA obviously dropped when the percentage of alkali liquid exceeded $30 \%$, whereas with BA, RHA and MK, the strength increased as the quantity of alkali liquid increased.

However, the $100 \%$ RHA and $100 \%$ BA were inappropriate to produce geopolymers because of their low compressive strength results. The reasons of low strength, probably, arise from the high $\mathrm{Si} / \mathrm{Al}$ molar ratio as the percentage of $\mathrm{SiO}_{2}$ contents of RHA and BA were 94.25 and 75.39, respectively, shown in Table 1. Therefore, it was thought to mix RHA and BA with FA in order to increase amount of $\mathrm{Al}_{2} \mathrm{O}_{3}$ which was brought from FA mainly and the $\mathrm{Si} / \mathrm{Al}$ molar ratio would be implied to decrease. The percentage of alkali liquid for geopolymer was suitably used between 30$40 \%$.

3.2. Effect of $\mathrm{Si} / \mathrm{Al}$ molar ratio and $\mathrm{Na} / \mathrm{Al}$ molar ratio on compressive strength

Table 2 Compressive strength, $\mathrm{Si} / \mathrm{Al}$ molar ratio and $\mathrm{Na} / \mathrm{Al}$ molar ratio

\begin{tabular}{|l|c|c|c|}
\hline \multicolumn{1}{|c|}{ Formulae } & $\begin{array}{c}\text { Compressive } \\
\text { strength }(\mathrm{MPa})\end{array}$ & $\begin{array}{c}\mathrm{Si} / \mathrm{Al} \\
\text { molar ratio }\end{array}$ & $\begin{array}{c}\mathrm{Na} / \mathrm{Al} \\
\text { molar ratio }\end{array}$ \\
\hline FA20BA80L40 & 3.01 & 7.47 & 1.14 \\
\hline FA20RHA80L40 & 2.63 & 16.2 & 2.06 \\
\hline FA20MK80L40 & 25.09 & 1.27 & 0.25 \\
\hline FA50BA50L40 & 16.16 & 4.06 & 0.73 \\
\hline FA50RHA50L40 & 5.07 & 5.66 & 0.88 \\
\hline FA50MK50L40 & 31.89 & 1.41 & 0.30 \\
\hline FA80BA20L40 & 11.13 & 2.48 & 0.53 \\
\hline FA80RHA20L40 & 12.28 & 2.80 & 0.56 \\
\hline FA80MK20L40 & 21.37 & 1.62 & 0.38 \\
\hline
\end{tabular}




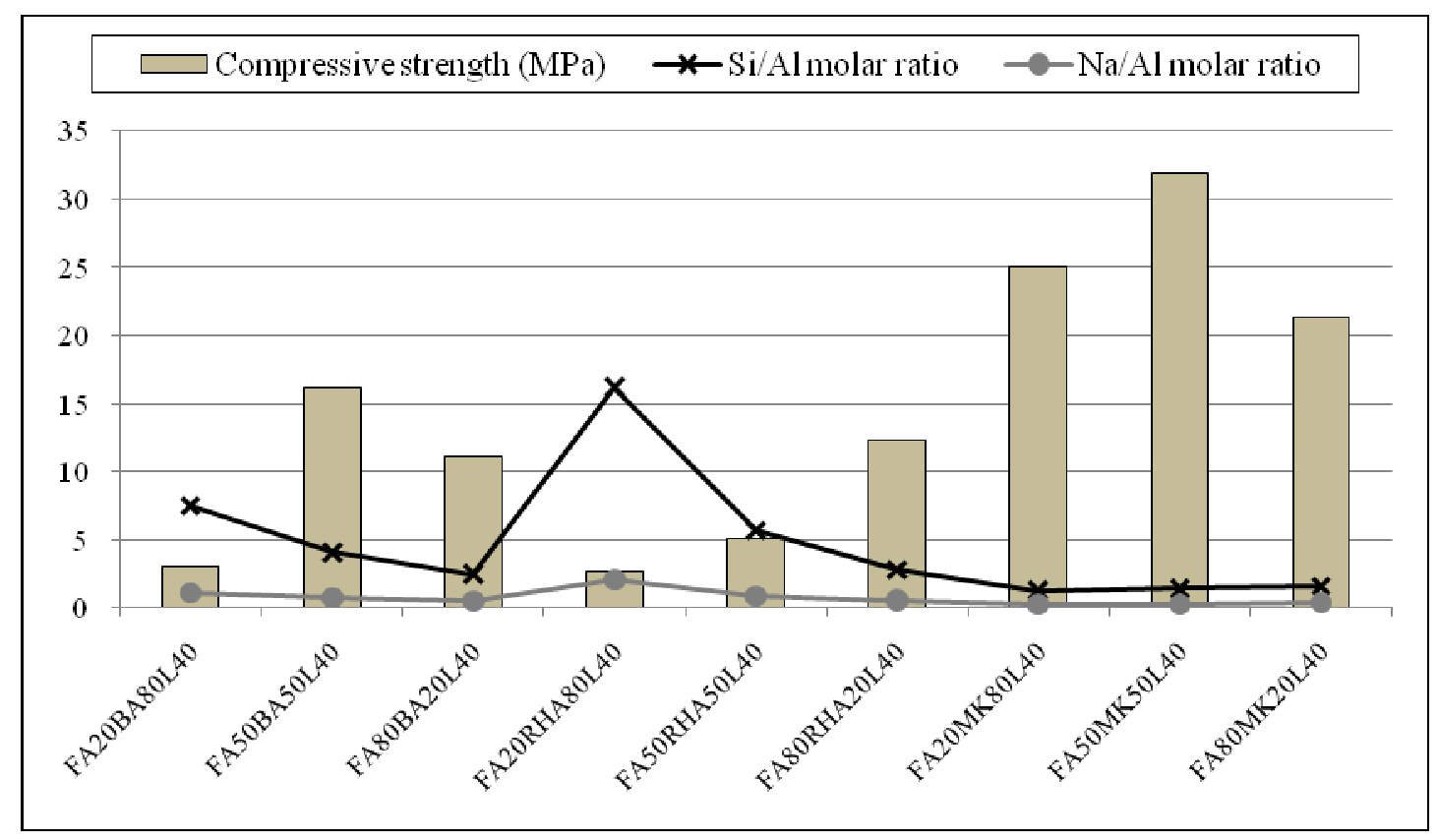

Fig. 3 Compressive strength vs. quantity of pozzolanic materials

The results of compressive strength of geopolymer specimens were shown in Fig. 3 at $40 \%$ alkali liquid and FA: other pozzolans (e.g. BA, RHA and MK) as 20:80, 50:50 and 80:20. The $50 \%$ FA-50\% MK performed the maximum compressive strength (31.89 MPa) whereas the $20 \% \mathrm{FA}-80 \%$ RHA performed the minimum (2.63 MPa). It was clearly found that the compressive strength of samples of BA and RHA mixed with FA, in Fig. 3, were much higher than those of only BA and RHA, in Fig. 2. For samples of MK mixed with FA and those of only $\mathrm{MK}$, the compressive strength of them was similar because both materials have similar chemical compositions. It was interesting to consider the $\mathrm{Si} / \mathrm{Al}$ molar ratio and $\mathrm{Na} / \mathrm{Al}$ molar ratio with the compressive strength. In Fig. 3, the higher than $20 \mathrm{MPa}$ compressive strength performed with the $\mathrm{Si} / \mathrm{Al}$ molar ratio the value between 1 and 2 and $\mathrm{Na} / \mathrm{Al}$ molar ratio less than 1.

\subsection{Water absorption, density and porosity}

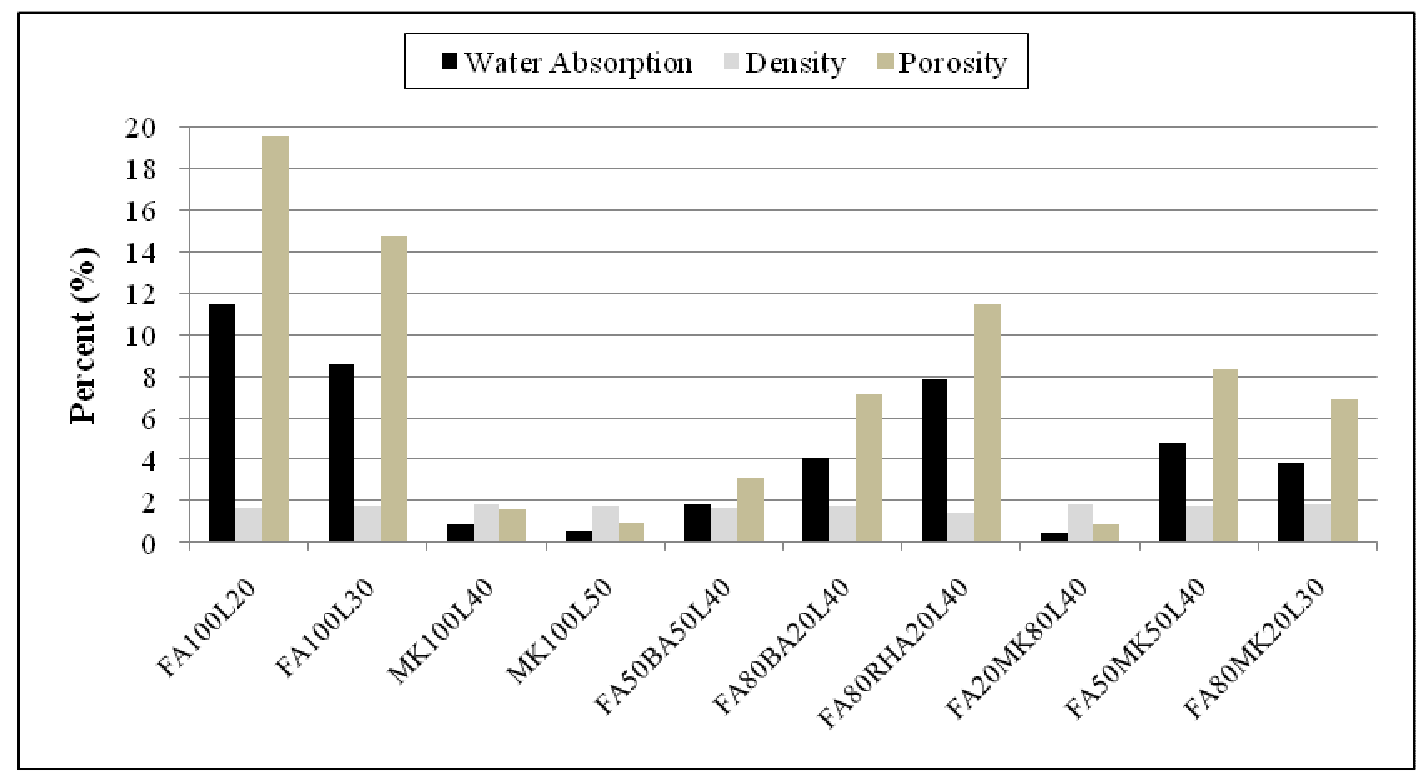

Fig.4 Water absorption, density and porosity 
From Fig. 4, the maximum water absorption (11.43\%) and porosity (19.52) were earned from FA100L20. The minimum water absorption $(0.46 \%)$ and porosity $(0.83)$ were received from FA20MK80L40. The water absorption of specimens was present in the same trend as the porosity. Each specimen has the comparable density. There were some specimens such as the $100 \%$ BA and $100 \%$ RHA not stable in water. The MK geopolymers present obviously low water absorption and porosity while FA geopolymers did oppositely. If these physical properties were compared with compressive strength, it was found that the lower water absorption and porosity, the higher compressive strength.

\section{Conclusion}

1. The compressive strength of geopolymers increased with the percentage of alkali liquid.

2. The $\mathrm{Si} / \mathrm{Al}$ molar ratio of the value between 1 and 2 and $\mathrm{Na} / \mathrm{Al}$ molar ratio of less than 1 were appropriate to produce geopolymers.

3. FA increased the amount of $\mathrm{Al}_{2} \mathrm{O}_{3}$ when mixed with $\mathrm{BA}$ and $\mathrm{RHA}$ and caused the $\mathrm{Si} / \mathrm{Al}$ molar ratio to decrease.

4. The maximum compressive strength was gained from FA50MK50L40 specimens.

5. The minimum water absorption and porosity were received from FA20MK80L40 specimens.

\section{Acknowledgement}

The author would like to acknowledge the instrument and raw materials supports of Department of Science Service, Ministry of Science and Technology, Bangkok, Thailand and would like to thank Department of Materials and Environmental Engineering, University of Modena and Reggio Emilia, Modena, Italy for new and great experiences.

\section{References}

[1] Davidovits J. (2000), Global Warming Impact on the Cement and Aggregates Industries.

[2] McCaffrey R. (2002), Climate Change and the Cement Industry, Global Cement and Lime Magazine, (Environmental Special Issue), 2002, pp. 15-19.

[3] Hardjito D. and Rangan B.V. (2005). Development and Properties of Low-calcium Fly ash based Geopolymer Concrete.

[4] Chen H.J., Ten T. and Chen K.H. (2003). Use of Building Rubbles as Recycled Aggregates. Cem Concr Res 2003; 33(1):pp.125-32.

[5] Chindaprasirt P., Kanchanda P., Sathonsaowaphak A. and Cao H.T. (2007). Sulfate Resistance of BlendedCcements Containing Fly Ash and Rice Husk Ash. Constructor Build Mater 2007; 21(6):1356-61.

[6] Shvarzman A., Kovlar K., Grader G.S. and Shter G.E. (2002). The Effect of Dehydroxylation/Amorphization Degree on Pozzolanic Activity of Kaolinite. Cement and Concrete Research 33 (2002) pp. 405-416.

[7] ASTM C 618, (2001). Standard specification for coal fly ash and raw or calcined natural pozzolan for use as a mineral admixture in concrete. Annual book of ASTM standards 04.0. pp. 310-313. 